Vol. 19(2010): 13-23.

\title{
Effects of birch tar oils on soil organisms and plants
}

\author{
Marleena Hagner ${ }^{1}$, Tiina Pasanen ${ }^{1}$, Bengt Lindqvist ${ }^{2}$, Isa Lindqvist ${ }^{2}$, Kari Tiilikkala ${ }^{2}$, \\ Olli-Pekka Penttinen ${ }^{1}$ and Heikki Setälä ${ }^{1 *}$ \\ ${ }^{I}$ Department of Ecological and Environmental Sciences, University of Helsinki, Niemenkatu 73, FI-15140 Lahti, \\ Finland,*e-mail: heikki setala@helsinki.fi \\ ${ }^{2}$ MTT Agrifood Research Finland, Plant Production Research, Rillitie 1, FI-31600 Jokioinen, Finland
}

\begin{abstract}
The use of birch tar oil (BTO) is a new innovation in plant and animal protection working against various weeds, harmful insects and rodents. Due to its novelty as a biocide/repellent/plant protection product, no comprehensive information on the effects of BTO on non-target soil organisms is available. In this study we examined the impact of BTO on non-target soil organisms (enchytraeids, nematodes and soil microbes) and plants using laboratory toxicity tests and field experiments. In addition, we determined the $\mathrm{LC}_{50}$ value of BTO to the earthworm Aporrectodea caliginosa and the $\mathrm{EC}_{50}$ value of BTO to the offspring production of the collembolan Folsomia candida. The effects of BTO on soil fauna were mostly insignificant. BTO seemed to be detrimental to the growth of plants directly after application, but this effect was short-term; after a period of 2.5 months, the growth of most of the plant species recovered completely from the application. The $\mathrm{LC}_{50}$ for $A$. caliginosa was $6560 \mathrm{mg} \mathrm{BTO} \mathrm{kg}^{-1}$ dry soil and $\mathrm{EC}_{50}$ for juvenile production of $F$.

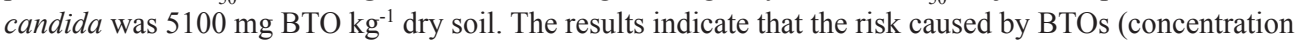
$500-1360 \mathrm{l} \mathrm{ha}^{-1}$ ) to the soil environment is insignificant and short-term as compared to the many chemical products applied for similar purposes.
\end{abstract}

Key-words: birch tar oil, plant protection, bio control, enchytraeids, nematodes, soil microbes, ecotoxicology

\section{Introduction}

The impact of pesticides on soils, their biota, and functions have become a matter of considerable concern especially in agriculture. Various pesticides are known to increase mortality of non-target soil organisms, thereby hampering the decomposition rate of organic matter (Bünemann et al. 2006) and thereby altering soil physico-chemical quality. Because of the various negative effects due to pesticides, there is an increasing need to develop biological methods for pest control. 
Hagner, M. et al. Birch oil toxity

Birch tar oil (BTO) is a byproduct of processing birch wood through a pyrolysis process to produce charcoal. There is ample anecdotal evidence suggesting the suitability of BTO for biocide and herbicide use, and/or repellents against insects, rodents, slugs and snails (Hagner et al. unpublished; personal observations by the authors, Hagner 2005, Hagner et al. 2010, Lindqvist et al. 2010, Salonen et al. 2008, Tiilikkala and Salonen 2008). Due to its novelty as a biological plant protection product, biocide, and repellent, and because of the high number of compounds evaporating in the pyrolysis process, no comprehensive information on the effective compounds of birch oil is available. Preliminary analyses indicate phenols to be one of the most promising groub of compounds in BTO acting as biocontrol agents, but various volatile compounds may also play a role.

According to international regulations (EU 1996), the ecotoxicological effects of chemicals on the environment are to be assessed before using chemicals in the field. To the best of our knowledge, no studies have been documented with regard to the ecotoxicological effects of BTO. In Finland large scale field experiments using biological plant protection products can not be established if the ecological effects of these products are not known. We therefore examined the general ecological effects of BTOs on target organisms before conducting the actual experiments. In the current study the effects of BTO on non-target soil organisms were tested using two kinds of birch tar oils, both derived from the same pyrolysis process: 1) BTO1, the liquid material originating during the early phase of the distillation process when the temperature remains below $380^{\circ} \mathrm{C}$, and 2) $\mathrm{BTO} 2$, the more viscous component generating at the end of the process when temperature rises to $400{ }^{\circ} \mathrm{C}$. BTO1 is effective against many weeds and insects and can be used as a herbicide and insecticide for example in potato fields (personal observation by the authors), while BTO2 has been shown to be an effective molluscicide (Hagner 2005, Linqvist et al. 2010).

This study is part of a larger research programme in which the effect of BTOs as a mollusc repellent (Lindqvist et al. 2010) and their ecotoxi- cological effects on both terrestrial (the current study) and aquatic (Hagner et al. 2010) organisms were investigated. Here we aimed at 1) determining the ecotoxicological effects of BTO's on non-target soil organisms and plants, and 2) to determine the lethal concentration $\left(\mathrm{LC}_{50}\right)$ value and the no observed effect concentration (NOEC) value for the earthworm Aporrectodea caliginosa, and the effective concentration $\left(\mathrm{EC}_{50}\right)$ value and the NOEC value for the reproduction of the springtail (collembolan), Folsomia candida.

\section{Material and methods}

\section{Ecological effects of BTOs on non-target soil organisms and plants - field investigations}

The ecotoxicological effects of BTOs on soil organisms were monitored via changes in soil fauna and plant populations. Three different groups of organisms covering various trophic levels were chosen: enchytraeid worms (mostly omnivorous), nematodes (covering several trophic positions), and soil microbes (primary decomposers). Relatively high doses of BTO1 were used in the experiments because we aimed at getting information about the highest possible risks of the substance. Further, an effective control of perennial weeds is likely to require high doses $\left(1.36 \mathrm{dl} \mathrm{m}^{-2}\right)$ of this substance (Lindqvist et al., unpublished data). When used for weed control of annual crops the required dose of BTO is about one-third, and for controlling pest insects about a tenth of the dose applied for perennial grass control. In the toxicity tests we mostly applied BTO1 due to its higher viscosity which renders it use more convenient than that of BTO2.

In the first experiment, referred to as a "garden experiment", six $2 \mathrm{~m}^{2}$ plots, enclosed with wooden fences (height $30 \mathrm{~cm}$ ), were constructed in June 2003 in the city of Lahti. The plots were established in five home gardens, each containing two replicate plots of each of the three treatments (see below). 
Vol. 19(2010): 13-23.

No attention was paid to possible differences in soil characteristics between the study sites. Dominant plant species in the yards were Poa sp. and Festuca sp. (Poaceae), Taraxacum officinale (Asteraceae) and Trifolium repens (Fabaceae). In one yard Aegopodium podagraria (Apiaceae) was abundant. Two leaf-litterbags (mesh size of $1 \mathrm{~mm}$ ) containing $2 \mathrm{~g}$ (dry mass) of Calamagrostis arundinacea (Poaceae)-leaf litter was placed in the soil to a depth of ca. $1 \mathrm{~cm}$ in each plot to examine the effects of BTOs on decomposition rate. Three treatments were established in each area: plots were sprayed with 1) BTO1 (corresponding to the amount of 0.5 $\left.\left.\mathrm{dl} \mathrm{m}{ }^{-2} ; \mathrm{n}=10\right), 2\right)$ BTO2 $\left(0.5 \mathrm{dl} \mathrm{m}^{-2} ; \mathrm{n}=10\right)$ and 3$)$ tap water ( $=$ control; $\mathrm{n}=10$ in each treatment). BTOs (and water control) were sprayed on the $2 \mathrm{~m}^{2}$ area using a compressed air pump once at the start of the study. Because the weather during the entire study period was dry and warm, water (2 1) was sprayed weekly on to each plot. Two soil samples (Ø $5 \mathrm{~cm}, 5 \mathrm{~cm}$ deep) were taken from each plot at $9,17,38$ and 70 days after establishing the experiments. The samples were stored (1-20 days; so that the mean storage time for the soils in each of the three treatment was the same) at $5{ }^{\circ} \mathrm{C}$ and the numbers of nematodes and enchytraeids were counted (for methods, see below). The effect of BTOs on plants (total plant coverage \%) was estimated in concurrently with taking the soil samples. At the final sampling, plants were harvested at randomly chosen $50 \times 50 \mathrm{~cm}^{2}$ areas in each plot, identified, dried $\left(24 \mathrm{~h}, 105^{\circ} \mathrm{C}\right)$ and weighed. The leaf-litter bags were removed and the contents dried ( $24 \mathrm{~h}$, $105^{\circ} \mathrm{C}$ ) and weighed.

The second experiment, referred to as the "field experiment", was carried out in an experimental field in central Finland (MTT Agrifood Research Finland, Toholampi), from mid June to late July 2005. An arable field containing numerous weed species and situated between two turnip rape fields, was divided into ten contiguous plots $(1 \mathrm{~m} \times 2 \mathrm{~m})$. Five randomly chosen plots were sprayed with BTO1 (1.36 $\left.\mathrm{dl} \mathrm{m}^{-2}\right)$ once at the start of the study using a compressed air pump. The control plots (n $=5$ ) were treated with water only. The experiment was conducted over 42 days, within which time soil samples were taken at 4, 10, 20, 29 and 42 days after the initiation of the study. At each sampling time, three soil samples ( $\varnothing 4 \mathrm{~cm}, 5 \mathrm{~cm}$ deep) were taken from each plot. The samples were stored in cooling boxes and transported to the laboratory for analysis of nematodes numbers, the biomass of enchytraeids, and the activity and biomass of soil microbes (for methods, see below).

\section{Toxic effects of BTOI on soil organisms and plants - mesocosm studies}

Experiment 1 was established as a mesocosm study at the garden area of the Department of Ecological and Environmental Sciences, University of Helsinki, Lahti, in summer 2004. The experimental design consisted of 75 mesocosms established in $1500 \mathrm{ml}$ glass jars $(\varnothing 10 \mathrm{~cm}$, height $19 \mathrm{~cm})$ filled with $400 \mathrm{~g}$ of fresh homogenised garden soil taken from a lawn adjacent to the Departmental building. Earthworms, roots and other larger plant remains were removed from the soil. Grass (Festuca rubra, Festuca ovina and Poa pratensis) seeds were sown in the mesocosms and kept under a plastic cover in natural light and temperature conditions in the garden. The weather during the study was variable with heavy rains (cumulative rainfall during the study was $147 \mathrm{~mm}$ ) to periods of dry and warm weather (average temperature during the study was $14.3^{\circ} \mathrm{C}$ ). After a stabilisation period of one month, three treatments were established, each with five replicates: the mesocosms were treated once with: 1) $100 \%$ BTO1 $\left(0.5 \mathrm{dl} \mathrm{m}^{-2}\right)$, 2) $5 \%$ BTO1 $(0.5 \mathrm{dl}$ $\left.\mathrm{m}^{-2}\right)$ and 3$)$ water $(=$ control $)$. We aimed at keeping the moisture content of the soil constant during the 7 -week study by adding $40-80 \mathrm{ml}$ of water weekly to each mesocosm. Five jars per treatment were randomly selected at day $1,7,20,29$ and 48 for destructive sampling in which the effects of the treatments on the numbers of nematodes, biomass of enchytraeids and microbial activity were examined. After the last sampling, the plants were uprooted, dried $\left(24 \mathrm{~h}, 105^{\circ} \mathrm{C}\right)$, and weighed.

Experiment 2 was identical to the experiment 1 described above except that the former was conducted in $200 \mathrm{ml}$ plastic bowls containing $100 \mathrm{~g}$ 
Hagner, M. et al. Birch oil toxity

moist, homogenised garden soil, and no plants were sown into the mesocosms. The mesocosms were weighted weekly and the water evaporated from the mesocosms during the 7-week study was replaced by adding tap water into the mesocosms. The bowls were kept at room temperature $\left(+22{ }^{\circ} \mathrm{C}\right)$ in constant darkness.

\section{Sampling of soil fauna}

Nematodes were extracted from $5 \mathrm{~g}$ (fresh) soil samples using the wet funnel method by Sohlenius (1979), and enchytraeids were extracted from 30$80 \mathrm{~g}$ soil samples using the wet funnel technique described by O'Connor (1955). The numbers of nematodes and enchytraeids were counted under a binocular microscope. In the mesocosm and field experiments the length of the enchytraeids was measured and the biomass of the different size classes was estimated using the formula described by Abrahamsen (1973). The total biomass of enchytraeids in the garden experiment was calculated using an average dry mass of $25 \mu \mathrm{g}$ per individual (Persson et al. 1980). The corresponding average dry mass of the nematodes was $0.03 \mu \mathrm{g}$ (Persson et al. 1980). Water content of the soil samples was determined by placing the soil into an oven $\left(70{ }^{\circ} \mathrm{C}\right)$ for 24 hours.

\section{Measuring of microbial activity and biomass}

Microbial activity was measured using basal respiration as an estimate. Microbial biomass was determined using the substrate induced respiration (SIR) method described by Anderson and Domsch (1978).

Basal respiration in the autotrophic (with plants) mesocosms was measured from $5 \mathrm{~g}$ soil samples during a period of $50 \mathrm{~h}$ using a respirometer (Nordgren 1988). Basal respiration in the field soil (100 $\mathrm{g}$ fresh soil) and in the mesocosm soil without plants were determined using EasyQuant infrared-carbon analyzer. Soils from the field site were stabilized for a period of $24 \mathrm{~h}$ before conducting the first measurement. Basal respiration in the mesocosms without plants was measured directly from the test jars so that an air sample was taken through a hole in the lid using the syringe from the head-space of the mesocosm. After this the hole was closed and a second air sample was taken two hours after closing the lid. Basal respiration was calculated from the difference in the amounts of $\mathrm{CO}_{2}$ between the two measurements. Microbial biomass (SIR), determined only from the field soils, was quantified using the EasyQuant infrared-carbonanalyzer two hours after an application of glucose (the application was performed immediately after the second measurement).

\section{Toxicity tests against Aporrectodea caliginosa and Folsomia candida}

The $\mathrm{LC}_{50}$ and NOEC values of BTO1 for the earthworm $A$. caliginosa were defined using adult individuals collected from an arable field close to the city of Lahti. In practice, Eisenia fetida is a standard earthworm species in terrestrial ecotoxicology tests in the EU, but in Northern Europe its occurrence is limited to sites rich in organic matter (Kula and Larink 1998). Therefore Aporrectodea caliginosa, a dominant endogeic earthworm species in the agro-ecosystems and grasslands (Kula and Larink 1998), was applied in the current study. The worms were maintained in the laboratory in the original field soil for a period of two weeks before the start of the experiment. The experiment was carried out according to the OECD guideline 207 (1984). Prior to the start of the experiment, BTO1, dissolved in distillate water, was mixed with artificial soil comprised of $70 \%$ coarse sand, $20 \%$ kaolinite clay and $10 \%$ finely ground Sphagnum peat, and adjusted to pH 6.5 with $\mathrm{CaCO}_{3}$. Moisture content was adjusted to $35 \%$ of the dry weight. The BTO1 concentrations used were 2695, 5380, 6725, 8070, 9420, 10760, 12200 and $13500 \mathrm{mg}$ BTO1 $\mathrm{kg}^{-1}$ dry soil $(\mathrm{n}=4)$. These concentrations were selected on the basis of results obtained in preliminary tests. Control soils $(n=4)$ received no BTO1. For each test, $750 \mathrm{~g}$ of 
Vol. 19(2010): 13-23.

the test medium was placed into each jar (vol. 1000 $\mathrm{ml}$ ) and ten earthworms (ranging from 300 to 600 mg wet mass), which had been conditioned for 24 hours in artificial soil and then washed quickly before use, were placed on the test medium surface. The earthworms were not fed during the 2-week study. After 7 and 14 days of exposure, alive worms were removed and counted. During the exposure, the microcosms were kept in a climate cabinet $(20 \pm 1$ ${ }^{\circ} \mathrm{C}$ ) in continuous light to keep the photophobic earthworms in the test jars during the test.

The effect of BTO1 ( $\mathrm{EC}_{50}$ and NOEC values) on the reproduction of springtails, F. candida, was determined using the protocol published by the International Standards Organization (ISO 1999). The springtails were derived from a pure culture maintained at the Department of Ecological and Environmental Sciences, University of Helsinki. The test was performed in $125 \mathrm{ml}$ glass jars $(\varnothing 11$ $\mathrm{cm}$, height $19 \mathrm{~cm}$ ), each filled with $30 \mathrm{~g}$ (wet mass) of artificial soil (70\% coarse sand, 20\% kaolinite clay and 10\% finely ground Sphagnum peat) and adjusted to $\mathrm{pH} 5.8$ with $\mathrm{CaCO}_{3}$. The test concentrations of BTO1 were 50, 85, 140, 235, 390, 655, 1090, 1820, 3030, 5055, 8425, 14040 and 23400 mg BTO1 $\mathrm{kg}^{-1}$ dry soil $(\mathrm{n}=5)$. These concentrations were selected on the basis of results obtained in preliminary tests. Control soils $(n=5)$ received no BTO1. BTO1 was added to the artificial soil with deionised water and the moisture content was adjusted to $25 \%$ of the dry weight. Soils were allowed to stabilise for one day prior to the experiment. Ten springtails (10-12 days old) were introduced to each replicate microcosm, and $2 \mathrm{mg}$ of dry yeast was placed on the soil surface as a diet. The lids of the microcosms were otherwise closed during the experiment but removed twice a week for aeration. Fresh yeast was added once a week. The experiment was carried out in a climate cabinet $\left(20^{\circ} \mathrm{C}\right)$ under a light:dark cycle $(16: 8 \mathrm{~h})$, and conducted for 28 days thus allowing sufficient time for the springtails to lay eggs. At the end of the experiment, the soil from each microcosm was mixed with $200 \mathrm{ml}$ of tap water and gently stirred. The number of springtails floating on the surface of the water was recorded.

\section{Statistical analysis}

To test for treatment effects in the field, a repeated measures ANOVA was conducted. When interaction between the time and treatment was observed the level of one treatment was fixed and the effects of the other treatment were studied within this level using one-way ANOVA (simple-effects model) (Zar 1999). The data was not always normally distributed and the variances were sometimes heterogeneous, even after data transformation. We were interested in the BTO -induced temporal patterns in the field studies and therefore repeated-measures (not available in non-parametric test packages) model was considered to be the most appropriate analysis, despite the fact that data transformation did not improve the data and as such warrants caution when interpreting the data.

Enchytraeid and nematode data from the garden soils were analyzed using a repeated measures ANOVA with the custom-model. Custom model -option was applied when the degrees of freedom did not suffice due to the incomplete experimental design. Using this model interactions between the factors are not calculated. To find out whether application of BTO1 results in changes in the plant community composition, the Principal Component Analysis (PCA) was applied.

To detect possible differences in the numbers of soil organisms between differentially treated mesocosms, a 2-way-ANOVA was used with time and BTO-treatment as factors. Data was not always normally distributed and the variances were sometimes heterogeneous. Transformations had no effect on data. Effects on plants in the mesocosms were analyzed by one-way-ANOVA, and differences between treatments were compared using Tukey's -test.

Probit analysis was used to determine $\mathrm{LC}_{50}$ values for earthworms with $95 \%$ confidence intervals. The effective concentration $\left(\mathrm{EC}_{50}\right)$ for juvenile production of Folsomia candida was calculated using DEBtox-package (2004). The DEBtox Growth Model was selected because it provided a better fit of reproduction data for BTO1 in F. candida. According to the Growth Model, the toxicant in- 
Hagner, M. et al. Birch oil toxity

fluences mother's energy allocation on offspring production. All statistical analyses were performed using the SPSS statistical package (SPSS 1999).

\section{Results}

\section{Effects of BTOs on soil fauna}

Birch tar oils had no consistent effects either on the numbers of enchytraeid worms in the garden soil in the city of Lahti (repeated measures ANOVA, $p=$ 0.642 ), or on their biomass in the Toholampi field study (repeated measures ANOVA, $p=0.85$ ). The biomass of enchytraeids in garden soil varied between 1.25 and $15 \mu \mathrm{g} \mathrm{g}^{-1}$ dry soil, and their biomass in the Toholampi field study ranged from 0 to $2.5 \mu \mathrm{g} \mathrm{g}^{-1}$ dry soil. Similarly, the effect of BTO1 on the biomass of enchytraeids in the mesocosm experiments without plants (2-way-ANOVA, $p=0.33$ ) and with plants was insignificant (2-way-ANOVA, $p=0.52$ ). The biomass of enchytraeid worms in these studies ranged from 0 to $22 \mu \mathrm{g} \mathrm{g}^{-1}$ dry soil.

The numbers of nematodes did not differ significantly between the treatments either in the garden experiment (repeated measures ANOVA, $p=0.117$ ), or in the mesocosm experiments without plants (2-way-ANOVA, $p=0.52$ ), or with plants (2-wayANOVA, $p=0.52$ ). In garden soil the number of nematodes fluctuated quite much being between 10.5 and 49.5 individual $\mathrm{g}^{-1}$ dry soil. In the mesocosm experiments with plants their numbers varied from 5.8 to 6.9 individual $\mathrm{g}^{-1}$ dry soil and in mesocosm without plants from 14.7 to 31.7 individual $\mathrm{g}^{-1}$ dry soil. In the Toholampi field study, the number of nematodes in BTO1 treated plots decreased at the last sampling time as compared to the control soils (ANOVA, simple effects, $p>0.05$ ) (Fig. 1).

BTO1 had no effect on microbial activity in the mesocosms with plants (2-way ANOVA, $p=0.52$ ). However, when plants were absent, microbial respiration in the mesocosms treated with 100\% BTO1 increased 1 day after BTO application, being significantly higher than in the control systems and in the mesocosms treated with 5\% BTO1 (Tukey, $p$
$<0.001$ ) (Fig. 2). Similar to the mesocosm experiment without plants, the field experiment showed that microbial activity was positively affected soon after addition of BTO1 (ANOVA, simple effets, $p$ $>0.05$ ) (Fig. 3). However, from day 9 onwards,

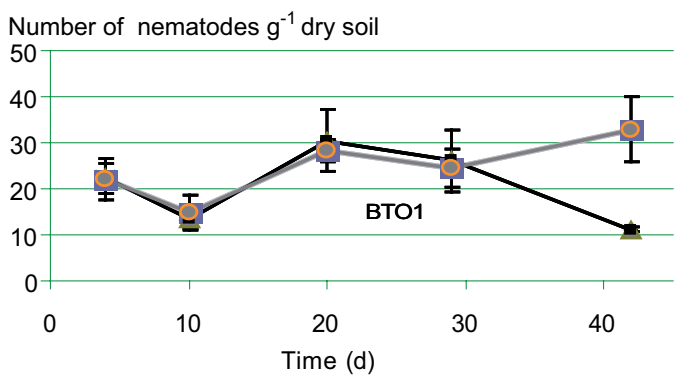

Fig 1 . The number (mean values $\pm S D, n=5$ ) of nematodes in the BTO1-treated (black line) and control plots (grey line) in the Toholampi field experiment

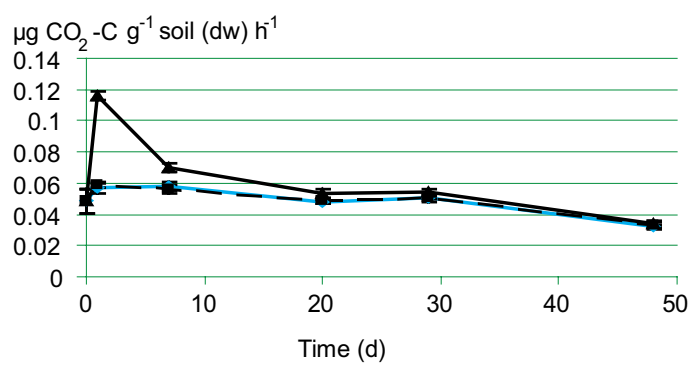

Fig 2. The effects of BTO1 treatments on the microbial activity during the mesocosms experiment without plants (mean values $+\mathrm{SD}, \mathrm{n}=5$ ). Blue line $=$ Control, black dashed line with squares $=5 \%$ BTO 1 , black line with triangles $=100 \%$ BTO 1 .

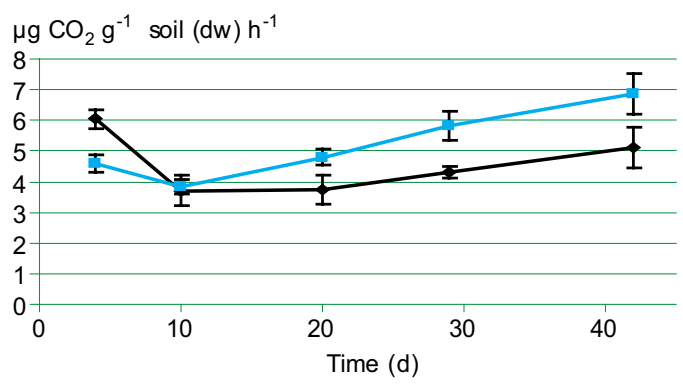

Fig 3. The effect of BTO1 on microbial activity at the Toholampi field experiment (mean values $+\mathrm{SD}, \mathrm{n}=5$ ). Blue line $=$ Control, black line $=$ BTO treated plots. 
Vol. 19(2010): 13-23.

the influence of BTO1 on microbial activity was negative (ANOVA, simple effects, $p>0.05$ ) (Fig. 3 ) and BTO1 had no effect on microbial biomass at any sampling time (repeated measures ANOVA, $p=0.38)$.

There was a rapid loss in leaf-litter mass during the garden experiment with no significant difference between the treatments (ANOVA, $p=0.384$ ). After 2.5 months, approximately $60 \%$ of the initial litter mass remained in the leaf-litter bags.

\section{Effects of BTOs on plants}

Plants showed signs of stress and began to wither immediately after BTO applications. In the garden plots, $40 \%$ and $60 \%$ of the total coverage of the plants withered within the first day of BTO1 and BTO2 application, respectively. However, plants started to recover one month after BTO treatments, and after 2.5 months no difference in plant biomass between the variously treated plots was observed (ANOVA, $p=0.532$ ). Aegopodium podagraria made an exception; only a fraction (5\% of total coverage) recovered in BTO2 treated plots, and $40 \%$ in BTO1 treated plots. Birch tar oils affected neither plant community composition nor plant species diversity as depicted from the results of the PCA analysis (results of the PCA-analysis not shown). The number of plant taxa varied between 2 and 14 at the experimental plots.

In mesocosms with plants, 100\% BTO1 had a negative effect (Tukey test, $p=0.01$ ) on plant biomass: 50 days after application, the biomass of $100 \%$ BTO1-treated plants was $84 \%$ less than in the control mesocosms. Application of 5\% BTO1 showed no consistent effects on plant biomass production (Tukey test, $p=0.76$ ).

\section{$\mathrm{EC}_{50}$-values for collembolas and earth- worms}

In $F$. candida $\mathrm{EC}_{50}$-value for juvenile production was $5100 \mathrm{mg} \mathrm{BTO} 1 \mathrm{~kg}^{-1}$ dry weight soil (S.D. $1280 \mathrm{mg}$ $\mathrm{kg}^{-1}$ ) (Fig. 4). No mortality (NOEC $=$ no observed effect concentration) occurred at $3033 \mathrm{mg}$ BTO $\mathrm{kg}^{-1}$ dry weight soil. Soil $\mathrm{pH}$ was variable during the treatment: at the beginning of the test it varied between 5.8 (controls) and 4.5 (23400 mg BTO $\mathrm{kg}^{-1}$ dry weight) (soil $\mathrm{pH}$ was not adjusted between treatments). The mortality in the control jars was low and the animals reproduced during the test. At highest test concentrations (8425-23400 mg BTO1 $\mathrm{kg}^{-1}$ dry soil), all springtails died. Variation in reproduction in controls did not exceed $30 \%$.

In the earthworm test 14-day $\mathrm{LC}_{50}$ for Aporrectodea caliginosa was $6560 \mathrm{mg}$ BTO $\mathrm{kg}^{-1}$ dry weight (95\% confidence limits 6323-6834 mg BTO $\mathrm{kg}^{-1}$ dry weight) (Fig. 5). NOEC value was 2694 mg BTO kg-1 dry weight. There was no mortality in the control jars.

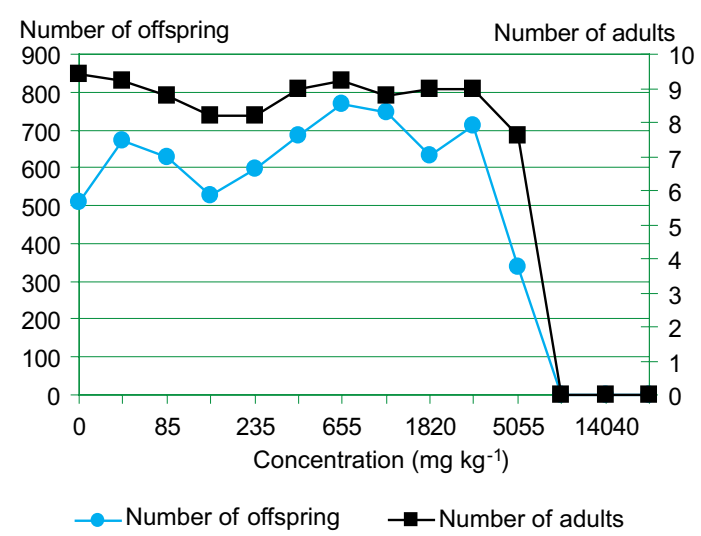

Fig 4. Chronic toxicity of BTO1 to F. candida adults (= lines with squares) and offspring (= lines with circles).

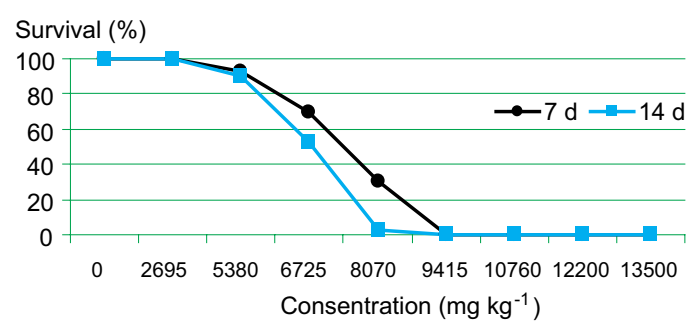

Fig 5. Survival rate of the earthworm A. caliginosa as a function of concentrations of BTO1 after 7 ( = lines with circles) and 14 ( = lines with squares) day exposure. 


\section{AGRICULTURAL AND FOOD SCIENCE}

\section{Hagner, M. et al. Birch oil toxity}

\section{Discussion}

\section{Field tests}

Enchytraeid worms, nematodes, soil microbes, earthworms and springtails were selected as test biota because they fullfill several criteria required for toxicity tests. They are present in a wide range of ecosystems, occur abundantly, play a key role in the functioning of the soil ecosystem, are easy to use, collect and culture, come into contact with a variety of stress factors (the soil solution, the solid phase, and the gaseous phase in soil), and are sensitive to environmental stresses (Didden and Römbke 2001, Römbke and Moser 2002, Schloter et al. 2003). Importantly, changes in the soil faunal community composition has been shown to markedly affect e.g. microbial and plant biomass and community composition, thereby controlling the functioning of the entire ecosystem (Bradford et al. 2002, Wardle et al. 2004).

BTOs proved to have a clear negative influence on plant biomass and species diversity in the home gardens, but this effect was short-term. Aegopodium podagraria, however, proved to be a sensitive species to BTOs with a poor recovery rate during the growing season. This species is a common, fastgrowing weed in gardens that has hitherto been tedious to control. The reason for the sensitivity of A. podagraria to BTOs remains open.

In the mesocosm experiment established under a plastic shelter, $100 \%$ BTO1 imposed a clear negative effect on the biomass of plants which continued up to 50 days post application. It is highly likely that the efficacy of BTO1 was reduced under field conditions due to rain and solar radiation, which can explain the differences between the field (open sky) and mesocosm (plastic roof) experiments.

BTO1 had no consistent effects on soil microbial biomass. Interestingly, both laboratory and field experiments suggest $100 \%$ BTO1 having a positive effect on microbial activity immediately after application. This is often a typical reaction when added resources are rapidly consumed by microbes (Meli et al. 2003). BTOs, being composed of numerous chemical compounds, supposedly include substances that are readily available for soil microbes. On the other hand, the enhanced respiration activity can, at least partly, be explainable by the so-called "gasping-effect", whereby toxic compounds enhance soil respiration but not microbial growth (Bååth 1989, Connell et al. 1999).

In the Toholampi field experiment, BTO1 had a negative influence on soil microbial activity in the last samplings. As depicted from the SIR results, BTO1 did not reduce microbial biomass. This can result from the withering of the plants in the BTOtreated plots. There is an increasing amount of evidence suggesting that the structure and activity of soil food webs can, by large part, be controlled by the living plant community (Wardle 2002, Bardgett 2005) regulating, for example, an amount of certain organic compounds in the soil by root excretion (Smolander and Priha 2003, Wardle et al. 2004). We hypothesize that in the BTO-treated plots in Toholampi, a decreased amount of root excudates by the dead/wilting plants lead to drastically reduced nutritional resources for the soil microflora causing the microbes to enter into a dormant state (Martikainen 2003). This negative effect is, however, likely to be short-term due to the resource input by the dead plant biomass later on in the growing season.

BTOs appeared to have little effect on enchytraeid worms and nematodes. This result was unexpected as both enchytraeids and nematodes are indirectly influenced by changes taking place above the ground (Wardle et al. 2004). The drastic changes by BTOs in the primary producers should therefore have cascaded down to the soil food web. That this proved not to be the case suggests that nematodes (as a group) and enchytraeid worms are less dependent on dead organic matter than on root exudates produced by living plants. Because BTOs had no effect on the survival of enchytraeids which are commonly considered as sensitive (Salminen and Haimi 1999, Salminen and Haimi 2001) keystone species (Huhta et al. 1998) living in the soil surface layer (Nurminen 1967), the direct and indirect effects of BTOs to soil food-webs appear insignificant. 
Vol. 19(2010): 13-23.

\section{Toxicity tests}

Earthworms are widely used in laboratory toxicity tests because of their important role in ecosystems and sensitivity to numerous chemical stressors (Didden and Römbke 2001). The $\mathrm{LC}_{50}$ (14 d) of BTO1 for Aporrectodea caliginosa was $6560 \mathrm{mg}$ BTO1 kg-1 dry soil. Most OECD countries follow the classification system where $\mathrm{LC}_{50}$-values being $>1000 \mathrm{mg} \mathrm{kg}^{-1}$ ( $\mathrm{kg}$ of dry soil weight) indicate pesticides to be practically nontoxic for earthworms (OECD 2003). The $\mathrm{LC}_{50}$ of BTO1 to Aporrectodea caliginosa was over six times higher. As far as we know, literature values for the toxicity of BTO1 in other species are not available for comparison. In general, the LC50 values are not comparable in experiments conducted on different experimental conditions and on different time scales. In the present study, the acute toxicity was within range of LC50 values reported in the literature indicating low toxicity of a single chemical (Russom et al. 1997).

Springtails are present in most soil habitats at densities of up to $10^{4}-10^{5} \mathrm{~m}^{-2}$ (Petersen and Luxton 1982) and play a vital role in the decomposition of organic material (Cragg and Bardgett 2001). The species $F$. candida is commonly applied as a test organism for estimating the effects of chemicals on non-target organisms (Fountain and Hopkin 2005) and it is among the most sensitive springtails to an array of chemicals (Chernova et al. 1995). The $\mathrm{EC}_{50}$ for the inhibition of juvenile production of $F$. candida was $5100 \mathrm{mg}$ BTO1 $\mathrm{kg}^{-1}$ dry soil.

Although the clear negative impact of this mixture on both the lethality of earthworms and the reproduction of collembolas was seen, the observed response is attributed to the combination of chemicals present in BTO1 and evidently the responses were not correlated with concentration of the main component producing toxicity. In theory, if a single chemical from the BTO1 mixture has a prominent lipophilicity and specific target site, it can alone give rise to the observed responses.

In the field, BTO1 acts as a non-selective herbicide by destroying virtually all growth of the aboveground parts of plants. Therefore, BTO treatments should be done before the emergence of cultivated seedlings. We have ample anecdotal evidence suggesting the suitability of BTO1 as a herbicide, for example in potato and carrot fields, and in the row width of berry shrubs and fruit trees.

To conclude, birch tar oils appeared to have no consistent, direct negative effects on enchytraeid worms, nematodes or soil microbial biomass when used at concentrations between 500-1360 $1 \mathrm{ha}^{-1}$. Instead, $100 \%$ BTO1 (500-1360 1 ha-1) showed a positive effect on microbial activity immediately after application, suggesting that easily utilized substances in BTO1 were rapidly consumed by microbes. Futhermore, the high $\mathrm{LC}_{50}$ value for the earthworm A. caliginosa indicates BTO1 to be practically nontoxic to earthworms. Altogether the risks caused by BTO1 in the soil environment are insignificant and short-term as compared to the many of chemical products applied for similar purposes.

In spite of the low environmental risks shown in this study a thorough investigation of the chemical composition of BTO is required. Although BTO is included in the worldwide substance database (CAS number 8001-88-5, American Chemical Society 2007), knowledge of the chemical composition of BTO is essential also for the EU registration of BTO as a biological plant protection product.

Acknowledgements. We are grateful to Asko Riihelä from the Lahti Region Environmental Service for finding the experimental sites for our studies. We warmly thank all the people who gave us permission to conduct experiments in their home yards. 
Hagner, M. et al. Birch oil toxity

\section{References}

Abrahamsen, G. 1973. Studies of body-volume, body-surface area, density and live weight of Enchytraeidae (Oligocaheta). Pedobiologia 13: 6-15.

American Chemical Society 2007: Homepage. Update (29 Apri4.209). Cite (13 June 209). Available on the internet: http://www.cas.org/expertise/cascontent/registry/regsyst.html?WT.mc_id $=$ casrn708\&WT.srch $=1$.

Anderson, J.P.E. \& Domsch, K.H. 1978. A physiological method for the quantitative measurement of microbial biomass in soils. Soil Biology and Biochemistry 10: 215-221.

Bardgett, R.D. 2005. The biology of soil: a community and ecosystem approach. Oxford University Press. 242 p.

Bradford, M.A., Jones, T.H., Bardgett, R.D., Black, H.I.J., Boag, B., Bonkowski, M., Cook, R., Eggers, T., Gange, A.C., Grayston, S.J., Kandeler, E., McCaig, A.E., Newington, J.E., Prosser, J.I., Setälä, H., Staddon, P.L., Tordoff, G.M., Tscherko, D. \& Lawton, J.H. 2002. Impacts of soil faunal community composition on model grassland ecosystems. Science 298: 615-618.

Bűnemann, E.K., Schwenke, G.D. \& Van Zwieten, L. 2006. Impact of agricultural inputs on soil organisms - a review. Australian Journal of Soil Research 44: 379-406.

Bååth, E. 1989. Effects of heavy metals in soil on microbial processes and populations: A review. Water, Air, and Soil Pollution 47: 335-379.

Chernova, N.M., Balabina, I.P. \& Ponomareva, O.N. 1995. Changes in population growth rate of sprintails (Collembola) under the influence of herbicides. Polskie Pismo Entomoogiczne 64: 91-98.

Connell, D., Lam, D., Richardson, B. \& Wu, R. 1999. Introduction to ecotoxicology. Blackwell Publishing. United Kingdom. 170 p.

Cragg, R.G. \& Bardgett, R.D. 2001. How changes in soil faunal diversity and composition within a tropic group influence decomposition processes. Soil Biology and Biochemistry 33: 2073-2081.

DEBtox, 2004. Publication v2.0. Department of Theoretical Biology, Vrije Universitet, Amsterdam, Netherlands.

Didden, W. \& Römbke, J. 2001. Enchytraeids as indicator organisms for chemical stress in terrestrial ecosystems. Ecotoxicology and Environmental Safety 50: 25-43.

EU (European Union) 1996. Technical guidance documents in support of the Commission Directive 93/67/ EEC on risk assessment for new notified substances and the Commission Regulation (EC) 1488/94 on risk assessment for existing substances, Brussels, Belgium.

Fountain, M.T. \& Hopkin, S.P. 2005. Folsomia candida (Collembola): A "standard" soil arthropod. Annual Review of Entomology 50: 201-222.

Hagner, M. 2005. Koivutisle torjunta-aineena: vaikutukset lehtokotiloon (Arianta arbustorum) ja maaperään (in Finnish). Masters thesis. University of Helsinki. Department of Ecological and Environmental Sciences. 39 p.

Hagner, M., Penttinen, O-P., Pasanen, T., Tiilikkala, K. \& Setälä, H. 2010. Acute toxicity of birch tar oil on aquatic organisms. Agricultural and Food Science 19: 24-33.

Huhta, V., Persson, T. \& Setälä, H. 1998. Functional implications of soil fauna diversity in boreal forests. Applied
Soil Ecology 10: 277-288.

ISO 1999. Soil quality-inhibition of reproduction of Collembola (Folsomia candida) by soil pollutants. Rep. No. ISO 11267:1999(E). Geneva. 16 p.

Kula, H. \& Larink, O. 1998. Tests on the earthworms Eisenia fetida and Aporrectodea caliginosa. In: Løkke, H. \& van Gestel, C. A. M. (ed.) Handbook of soil invertebrate toxicity tests. John Wiley \& Sons Ltd, Chichester. p. 95-112.

Lindqvist, I., Lindqvist, B., Tiilikkala, K., Hagner, M., Penttinen,O-P., Pasanen. T. \& Setälä, H. 2010. Birch tar oil is an effective mollusc repellent: field and laboratory experiments using Arianta arbustorum (Gastropoda: Helicidae) and Arion lusitanicus (Gastropoda: Arionidae). Agricultural and Food Science 19: 1-12.

Martikainen, P. 2003. Metsämaan mikrobisto -In: Mälkönen, E. (ed.), Metsämaa ja sen hoito (in Finnish). Karisto, Hämeenlinna. p. 101-114.

Meli, S.M., Badalucco, L., English, L.C. \& Hopkins, D.W. 2003. Respiratory responses of soil micro-organisms to simple and complex organic substrates. Biology and Fertility of Soils 37: 96-101.

Nordgren, A. 1988. Apparatus for the continuous longterm monitory of soil respiration rate in a large number of samples. Soil Biology and Biochemistry 20: 955-957.

Nurminen, M. 1967. Ecology of enchytraeids (Oligochaeta) in Finnish coniferous forest soil. Annales Zoologici Fennici 4: 147-157

O'Connor, F. B. 1955. Extraction of enchytraeid worms from a coniferous forest soil. Nature 175: 815-816.

OECD 1984. OECD guideline for testing of chemicals. No. 207. "Earthworm, Acute Toxicity Tests". Paris. Organization for Economic Development. 9 p.

OECD 2003. OECD environmemt, health and safety publications. Series on pesticides, No. 15. Persistent, bioaccumulative, and toxic pesticides in OECD member countries. $67 \mathrm{p}$.

Persson, T., Clarholm M., Lundkvist, H., Söderström, B. \& Sohlenius B. 1980. Trophic structure, biomass dynamics and carbon metabolism in a Scots pine forest. - In: Persson T (ed.), Structure and function of northern coniferous forest - an ecosystem study. Ecol Bull (Stockholm) 23: 419-459.

Petersen, H. \& Luxton, M. 1982. A comparative analysis of soil fauna populations and their role in decomposition processes. Oikos 39: 288-388.

Russom, C.L., Bradbury, S.P., Broderius, S.J., Hammermeister, D.E. \& Drummond, R.A. 1997. Predicting modes of toxic action from chemical structure: acute toxicity in the fathead minnow (Pimephales promelas). Environmental Toxicology and Chemistry 16: 948-967.

Römbke, J. \& Moser, T. 2002. Validating the enchytraeid reproduction test: organisation and results of an international ringtest. Chemosphere 46: 1117-1140.

Salminen, J. \& Haimi, J. 1999. Horizontal distribution of copper, nickel and enchytraeid worms in polluted soil. Environmental pollution 104: 351-358.

Salminen, J. \& Haimi, J. 2001. Life history and spatial distribution of the enchytraeid worm Cognettia sphagnetorum (Oligochaeta) in metal-polluted soil: below-ground sink-source population dynamics? Environmental Toxicology and Chemistry 20: 1993-1999.

Salonen, J., Tiilikkala, K., Ruuttunen, P., Lindqvist, I. \& Lindqvist, B. 2008. Birch Tar Oil: A Potential Herbicide 


\section{AGRICULTURAL AND FOOD SCIENCE}

Vol. 19(2010): 13-23.

from the Forests of Finland. In: Abstracts of the 5th International Weed Science Congress. Weeds local problems/global challenge. Vancouver, British Columbia, Canada. p. 286-287

Schloter, M., Dilly, O. \& Munch, J.C. 2003. Indicators for evaluating soil quality. Agriculture, Ecosystems and Environment 98: 255-262.

Smolander, A. \& Priha, O. 2003. Puulajin merkitys metsämaan viljavuuden hoidossa. In: Mälkönen, E. (Ed.), Metsämaa ja sen hoito (in Finnish). Karisto, Hämeenlinna. p. $155-158$

Sohlenius, B. 1979. A carbon budget for nematodes, rotifers and tardigrades in a Swedish coniferous forest soil. Holarctic Ecology 2: 30-40.
SPSS, 1999. SPSS for Windows 10.0. publication 9.0.1. SPSS, Chicago.

Tiilikkala, K. \& Salonen, J. 2008. Birch tar oil (BTO) a potential biological pesticide from forests. In: Biorefinery Joint Call Info Day. Information Booklet. Bryssel. p. 85

Wardle, D.A., Bardgett, R.D., Klironomos, J.N,. Setälä, H., van der Putten, W.H. \& Wall, D.H. 2004. Ecological linkages between aboveground and belowground biota. Science 304: 1629-1633.

Wardle, D.A. 2002. Communities and ecosystems - linking the aboveground and belowground components, Princeton University Press, Princeton. $392 \mathrm{p}$.

Zar, J.H. 1999. Biostatistical analysis. 4 th edition. PrenticeHall, Inc. Englewood Cliffs, New Jersey. 736 p. 